\title{
Separation and purification of rebaudioside A from extract of Stevia Rebaudiana leaves by macroporous adsorption resins
}

\author{
Masoumeh Anvari ${ }^{1}$,Gholam Khayati ${ }^{* *}$ \\ ${ }^{1}$ Islamic Azad University, Department of Biology, Faculty of Sciences, Rasht Branch, Rasht, Iran \\ ${ }^{2}$ University of Guilan, Department of Chemical Engineering, Technical Faculty, P.O. Box 41635-3756, Rasht, Iran \\ "Corresponding author: e-mail: khayati@guilan.ac.ir
}

\begin{abstract}
The separation and purification of rebaudioside A from Stevia rebaudiana crude extracts (Steviosides) by macroporous resin were optimized by Taguchi orthogonal array (OA) experimental design methodology. This approach was applied to evaluate the influence of five factors (adsorption temperature, desorption time, elution solution ratio, adsorption volume and type of resin) on the rebaudioside A yield. The percentage contribution of each factor was also determined. The results showed that elution solution ratio and adsorption volume made the greatest $(59.6 \%)$ and the lowest $(1.3 \%)$ contribution, respectively. The results showed that the Taguchi method is able to model the purification of rebaudioside A process well $\left(R^{2}>0.998\right)$ and can therefore be applied in future studies conducted in various fields. Adsorption temperature $35^{\circ} \mathrm{C}$, desorption time $60 \mathrm{~min}$, elution solution ratio 3 , adsorption volume $200 \mathrm{ml}$ and HPD-400 as resin were the best conditions determined by the Taguchi method.
\end{abstract}

Keywords: rebaudioside A, Stevia rebaudiana, design of experimental, taguchi orthogonal array.

\section{INTRODUCTION}

Stevia rebaudiana Bertoni, belonging to the Compositae family, is a sweet herb native to South America. The plant has been cultivated in Guilan province (Iran) for a few decades. Stevia leaves contain diterpene glycosides, namely, stevioside, rebaudiosides A-F, steviolbioside, and dulcoside $\mathrm{A}$, which are responsible for the typical sweet taste ${ }^{1}$. Although stevioside and rebaudioside A have similar chemical structures ${ }^{2}$, they have significant differences in sweetness and taste quality, so stevioside tastes about 270-280 times, and rebaudioside A tastes about $350-450$ times sweeter than $0.4 \%$ sucrose solution ${ }^{3}$. Moreover, rebaudioside A has the best quality, close to that of glucose 4 . Thus, rebaudioside A is considered to be the ideal components in stevioside, and the separation of high content of rebaudioside A from stevioside has attracted increasing attention in the stevioside industry.

Various methods have been reported to separate rebaudioside A from stevioside ${ }^{5-6}$. However, there are some disadvantages when these methods are applied in industrial production. Alternatively, adsorption separation technology of macroporous adsorption resin is a relatively new separation method and displays an obvious superiority in industrial production since macroporous resins have a high adsorption capacity, certain selectivity, low cost, easy regeneration and have a good stability ${ }^{7-8}$. Macroporous Adsorption Resin (MAR) has been extensively used in the fields of chromatography analysis, water treatment industry and etc. However, little studies on their use for the extraction of natural substances such as rebaudioside have been performed.

There are several important factors such as elution ratio, desorption time, adsorption temperature, adsorption volume, adsorption time and etc that affect on stevioside and rebaudiosides extractability from Stevia rebaudiana of extracts. The classical method of studying of one variable at a time may be effective in some processes, but fails to consider the combined effects of several factors involved. Statistical experimental designs can collectively optimize all the affecting parameters to eliminate the limitations of a single-factor optimization process. The traditional method of optimization involves varying one factor at a time, while keeping the others constant. This strategy requires a relatively large number of experiments and frequently fails to anticipate the optimal conditions. This essential shortcoming is due to the inability of the approach to consider the effects of possible interactions between factors. The deficiency can be overcome by applying more efficient, statistically based experimental design. This approach has been successful for enhancing yields of enzyme production and propionic acid extraction in our experiments ${ }^{9-10}$. Thus, in the present study was used an effective statistical technique for optimizing extraction process and maximize rebaudioside A yield.

In this respect, Taguchi orthogonal design is important tools to determine the optimal process conditions. The advantages of using the Taguchi method are that many more factors can be screened and optimized simultaneously and much quantitative information can be extracted by only a few experimental trials. Therefore, these methods have been extensively applied in parameter optimization and process control ${ }^{11}$.

The aim of the current study was to investigate the separation and purification of rebaudioside A from stevia rebaudiana leaves using macroporous resin, and extraction factors optimization was performed using fractional factorial design of orthogonal array of Taguchi methodology.

\section{EXPERIMENTAL}

\section{Material}

Stevia rebaudiana leaves were harvested from the plantation fields in Rasht, Iran. The leaves were dried at room temperature for 5 days and stored at the cold storage.

Two types of macroporous resins were provided from TEMAD Company (Tehran, Iran) that their physical properties were listed in Table 1. They were pretreated by dipping them in ethanol for $48 \mathrm{~h}$, then washing with ultrapure water thoroughly to remove the monomers 
Table 1. Physical properties of the macroporous resins used

\begin{tabular}{|l|l|c|c|l|}
\hline Trade name & Functional group & Average pore [nm] & Particle diameter [mm] & Polarity \\
\hline HPD 600 & Acylamino polystyrene & 7.1 & $0.3-1.25$ & Strong-polar \\
\hline HPD 400 & Polydivinyl benzene acrylic ester & 8.3 & $0.3-1.2$ & Middle-polar \\
\hline
\end{tabular}

and porogenic agents trapped inside the pores during the synthesis process.

All organic solvents and others chemicals were analytical grade and used without further purification.

\section{Preparation of crude sample}

Firstly, the leaves of $S$. rebaudiana $(10 \mathrm{~g})$ were extracted three times ( $1 \mathrm{~h}$ for each time) with $1000 \mathrm{ml}$ of boiling water, and all of the clear extracts were combined. The extracts were evaporated to condensation in a rotary evaporator at $60^{\circ} \mathrm{C}$. Final volume of concentrated raw solution was $500 \mathrm{ml}$ and it was used as feed in all experiments.

\section{Experimental design and statistical analysis}

The Taguchi method applies fractional factorial experimental designs, called orthogonal arrays, to reduce the number of experiments while obtaining statistically meaningful and worthwhile results. The selection of a suitable orthogonal array depends on the number of control parameters and their levels ${ }^{12}$. An experimental L16 array from the Taguchi method was applied for the optimization of the purified rebaudioside A. The five factors selected were: adsorption temperature $(35,40$, 45 and $\left.50^{\circ} \mathrm{C}\right)$, desorption time $(30,60,90$ and $120 \mathrm{~min})$, elution solution ratio (ethanol-ethyl acetate 1:1, 2:1, 3:1 and 4:1), adsorption volume (50,100, 150 and $200 \mathrm{ml}$ ) and type of resin (HPD-600 and HPD-400). The array and levels of the experimental factors are given in Table 2. For each experimental trial of the independent variables in the experimental design, the dependent parameter (rebaudioside A yield) was determined.

The L16 orthogonal array was selected by the Taguchi method. The number of experiments required is drastically reduced to 16 . This means that 16 experiments with different combinations of the parameters should be conducted to study the main effects and interactions, which in the classical combination method using full factorial experimentation would require $4^{4} \times 2^{1}=512$ experiments to capture the effective parameters.
Analysis of variance (ANOVA) was generated, and the effect of terms were determined. The significances of all terms were judged statistically by computing the p-value $<0.05$. The analysis of data and optimization process were generated using Minitab statistical software version 15.

All of experiments were repeated at least three times in order to acquire high accuracy and data are their three results averages. This procedure gave consistent and reproducible results.

\section{Adsorption/desorption experiments}

The extraction process was conducted on herb native variety cultivated in this area_(Guilan-Iran). Five $g$ of dry macroporous resins and different volumes of crude sample solution were put into Erlenmeyer flasks, with a stopper. Then, the Erlenmeyer flasks were shaken in shaking incubator for $4 \mathrm{~h}$ at different temperatures. After the adsorption equilibrium was reached, the resins were first washed by ultrapure water for five times, and then desorbed with $100 \mathrm{ml}$ ethanol-ethyl acetate solution in the Erlenmeyer flask in the incubation shaker at different times (Table 2). The desorption solution were evaporated to dryness, and dried at $100^{\circ} \mathrm{C}$ to constant weight. Thereafter, a certain amount of dry matter was dissolved in $25 \mathrm{ml} 70 \%$ ethanol-water solution and analyzed by HPLC.

\section{Analysis of samples}

The amount of rebaudioside A present in the each sample (before and after separation) was analyzed by HPLC ${ }^{13}$. Initially a calibration curve was prepared using standard rebaudioside A of $98 \%$ purity. Standard stock solutions were prepared in $70 \%(\mathrm{v} / \mathrm{v})$ ethanol-water solution $(3000 \mu \mathrm{g} / \mathrm{ml})$. Five additional levels were prepared by dilution of stock solutions $(1500,1000,500,250$ and $125 \mu \mathrm{g} / \mathrm{ml}$ ) with ethanol-water solution and stored at $4^{\circ} \mathrm{C}$. Finally, the rebaudioside A yield $\left(\frac{\mu g / m l}{\mu g / m l}\right)$ was defined as: rebaudioside $\mathrm{A}$ yield $=$ rebaudioside $\mathrm{A}$ in purified extract / rebaudioside A present in feed.

Table 2. Experimental L16 orthogonal array and results the rebaudioside A yield"

\begin{tabular}{|l|c|c|c|c|c|c|}
\hline \multirow{2}{*}{ Exp.No. } & \multicolumn{3}{|c|}{ Factor levels } & \multicolumn{2}{c|}{ Rebaudioside A yield $\left[\frac{\mu \mathrm{g} / \mathrm{ml}}{\mu \mathrm{g} / \mathrm{ml}}\right]$} \\
\hline & Adso. temp. $\left[{ }^{\circ} \mathrm{C}\right]$ & Deso. time [min] & Elu. ratio & Adso. Vol. [ml] & \multicolumn{2}{c|}{ Type of resin } \\
\hline 1 & 35 & 30 & 1 & 50 & HPD-600 & 0.204 \\
\hline 2 & 35 & 60 & 2 & 100 & HPD-600 & 0.379 \\
\hline 3 & 35 & 90 & 3 & 150 & HPD-400 & 0.450 \\
\hline 4 & 35 & 120 & 4 & 200 & HPD-400 & 0.771 \\
\hline 5 & 40 & 30 & 2 & 150 & HPD-400 & 0.332 \\
\hline 6 & 40 & 60 & 1 & 200 & HPD-400 & 0.414 \\
\hline 7 & 40 & 40 & 4 & 50 & HPD-600 & 0.486 \\
\hline 8 & 40 & 30 & 3 & 100 & HPD-600 & 0.182 \\
\hline 9 & 45 & 60 & 4 & 150 & HPD-600 & 0.121 \\
\hline 10 & 45 & 90 & 1 & 100 & HPD-600 & 0.514 \\
\hline 11 & 45 & 120 & 2 & 50 & HPD-400 & 0.514 \\
\hline 12 & 45 & 30 & 4 & 100 & HPD-400 & 0.368 \\
\hline 13 & 50 & 60 & 3 & HPD-400 & 0.518 \\
\hline 14 & 50 & 90 & 2 & 200 & HPD-400 & 0.271 \\
\hline 15 & 50 & 120 & 1 & 150 & HPD-600 & 0.268 \\
\hline 16 & 50 & HPD-600 & 0.207 \\
\hline
\end{tabular}

The initial concentration of the solution was $1.14 \mathrm{mg} / \mathrm{ml}$. 


\section{RESULTS AND DISCUSSION}

To the best of our knowledge, data of this process has not been reported so far.

\section{Effects of independent variables on responses}

Purification of stevioside and rebaudiosides from $S$. rebaudiana leaves depends on some factors, including ratio of elution solvent, time and the temperature of extraction, type of resin and etc ${ }^{\mathbf{1 4 - 1 5}}$. It is known that each extraction process requires specific operating conditions ${ }^{9}$. Taguchi experimental design is a good positive option for the optimization of chemical and biotechnological processes ${ }^{11}$. In this case, the influence of 5 factors i.e., adsorption temperature $\left({ }^{\circ} \mathrm{C}\right)$, desorption time $(\mathrm{min})$, ratio of elution solvent (ethanol-ethyl acetate $\mathrm{v} / \mathrm{v}$ ), adsorption volume $(\mathrm{ml})$ and type of resin chosen for optimization of purification of rebaudioside A from $S$. rebaudiana leaves by macroporous resins in Taguchi experimental design in 16 runs. The results of Taguchi experimental design show the efficiency of rebaudioside A yield ranging from $0.121-0.771$ corresponding to the combined effect of the five factors in their specific ranges (Table 2). The main
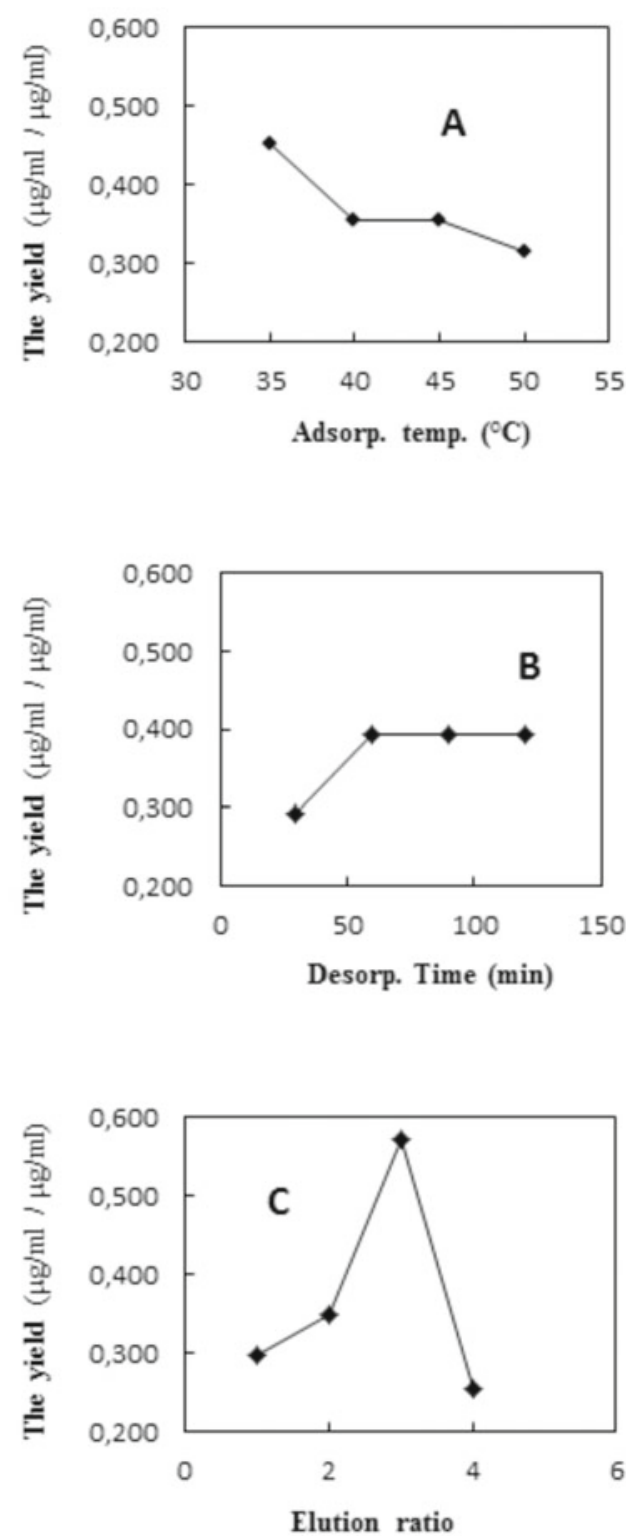

effects of each parameter are presented in Figure 1, which serve as a measure to view individual variables' contributions on the yield of rebaudioside A. This was estimated based on the averages of measurements made at the level of each factor.

In the present study, the effect of different adsorption temperature on purification of rebaudioside $\mathrm{A}$ was studied. It was found that yield decreased with the increase of adsorption temperature (Fig. 1A). This could be because of the adsorption of macroporous resin was always exothermic and a process of entropy increasing and rising temperature was unfavorable to adsorption ${ }^{16}$. $\mathrm{Li}$ et al. ${ }^{14}$ have also shown that high adsorption temperature is effective in reducing the purification of rebaudioside A.

The effect of desorption time on yield was shown in Figure 1B. It was seen that rebaudioside A yield increased with the extension of desorption time and reached the maximum at $60 \mathrm{~min}$. Similar findings have been reported by other workers also ${ }^{14,17}$. The results showed that a prolonged time beyond this period did not help to further increase the yield. The cost of purification process depends mostly upon the operating cost; there-
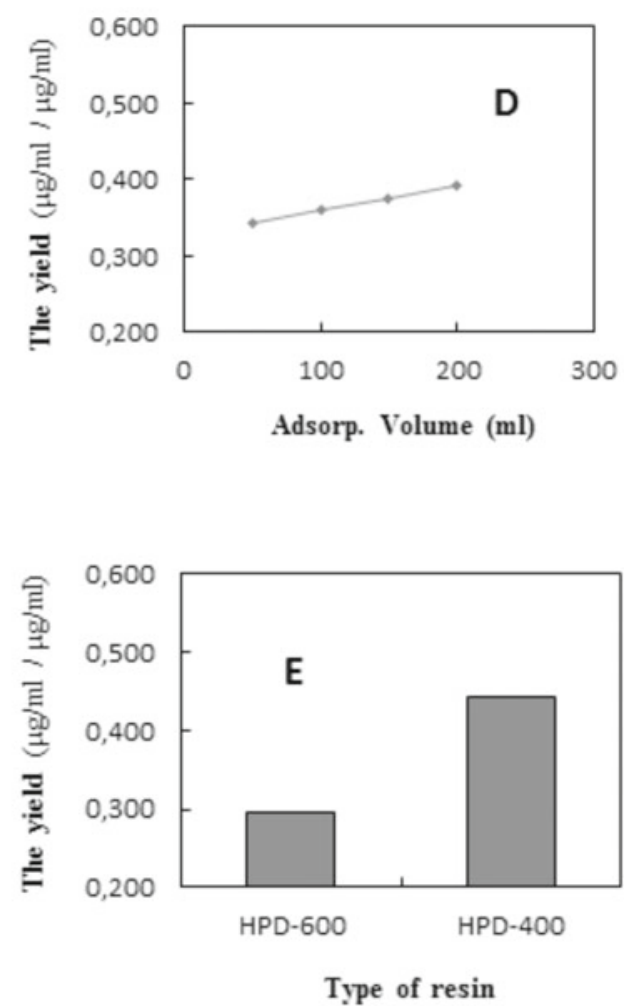

Figure 1. Main effects of the variables for the rebaudioside A yield based on the Taguchi experimental design results 
fore, a shorter desorption time period would increase profitability on an industrial scale.

In this study, four different elution ratios varying from 1:1 to 4:1 (ethanol /ethyl acetate $\mathrm{v} / \mathrm{v}$ ) were used. The highest rebaudioside A yield (0.572) was achieved at the ratio 3:1 (Fig. 1C). A decrease in yield was observed when the ratio of elution solvents was lower or higher than the optimum. This could be explained by the principle of the dissolution in a similar material structure ${ }^{17}$. As ratio of elution increased further, the ethanol in desorption system increased excessively, which made macroporous resins difficult to swell completely, and the adsorbed rebaudioside A was not easy to be desorbed from macroporous resins owing to the bigger molecule size and larger strict hindrance effect, yield decreased.

The relationship between adsorption volume and rebaudioside A yield was shown in Figure 1D. Yield increased linearly with increase volume of adsorption. It's probably due to the multiple partition equilibrium among various phases ${ }^{16}$ and the different affinity of macroporous resins to sugar solution.

The adsorption characteristics of macroporous resins are in close relation to chemical features and physical properties of resins. The selection of proper resins should be in accordance with the structures and polarities of resins, such as their pore diameters, pore volumes and surface areas ${ }^{18}$. Effect of resin type on rebaudioside A yield is illustrated in Figure 1E. The results showed that HPD-400 offered better adsorption and desorption capacity for rebaudioside A than other tested resin (HPD-600). It was observed that the adsorption and desorption performances of different resins were distinct. Since, rebaudioside A is a large and polar hydrocarbon molecule ${ }^{\mathbf{1 9}}$. Middle polar resin exhibited better adsorption and desorption capacity for rebaudioside $\mathrm{A}$ than other not only because of their polarity, but also because of their higher specific surface area $\left(700 \mathrm{~m}^{2} / \mathrm{g}\right)$ and bigger average pore diameter $(8 \mathrm{~nm})$. Obviously, the strong polar HPD-600 resin with low specific surface area $\left(255 \mathrm{~m}^{2} / \mathrm{g}\right)$ and small average pore diameter $(7 \mathrm{~nm})$ possessed bad adsorption and desorption capabilities for rebaudioside $\mathrm{A}$.

Adsorption temperature $35^{\circ} \mathrm{C}$, desorption time $60 \mathrm{~min}$, elution solution ratio 3, adsorption volume $200 \mathrm{ml}$ and HPD-400 as resin were the best conditions determined by the Taguchi method.

In the case of interaction effect of resin type and adsorption temperature the results showed that resin HPD-400 had the better extraction yield in all temperature compare with resin HPD-600 (Fig. 2A). In the case of interaction effect of desorption time and type of resin the results indicated that despite of better extraction yield with resin HPD-600 at 60 min the mean yield of extraction by resin HPD-400 was greater than resin HPD-400 (Fig. 2B). In the case of interaction effect of adsorption temperature and desorption time the results
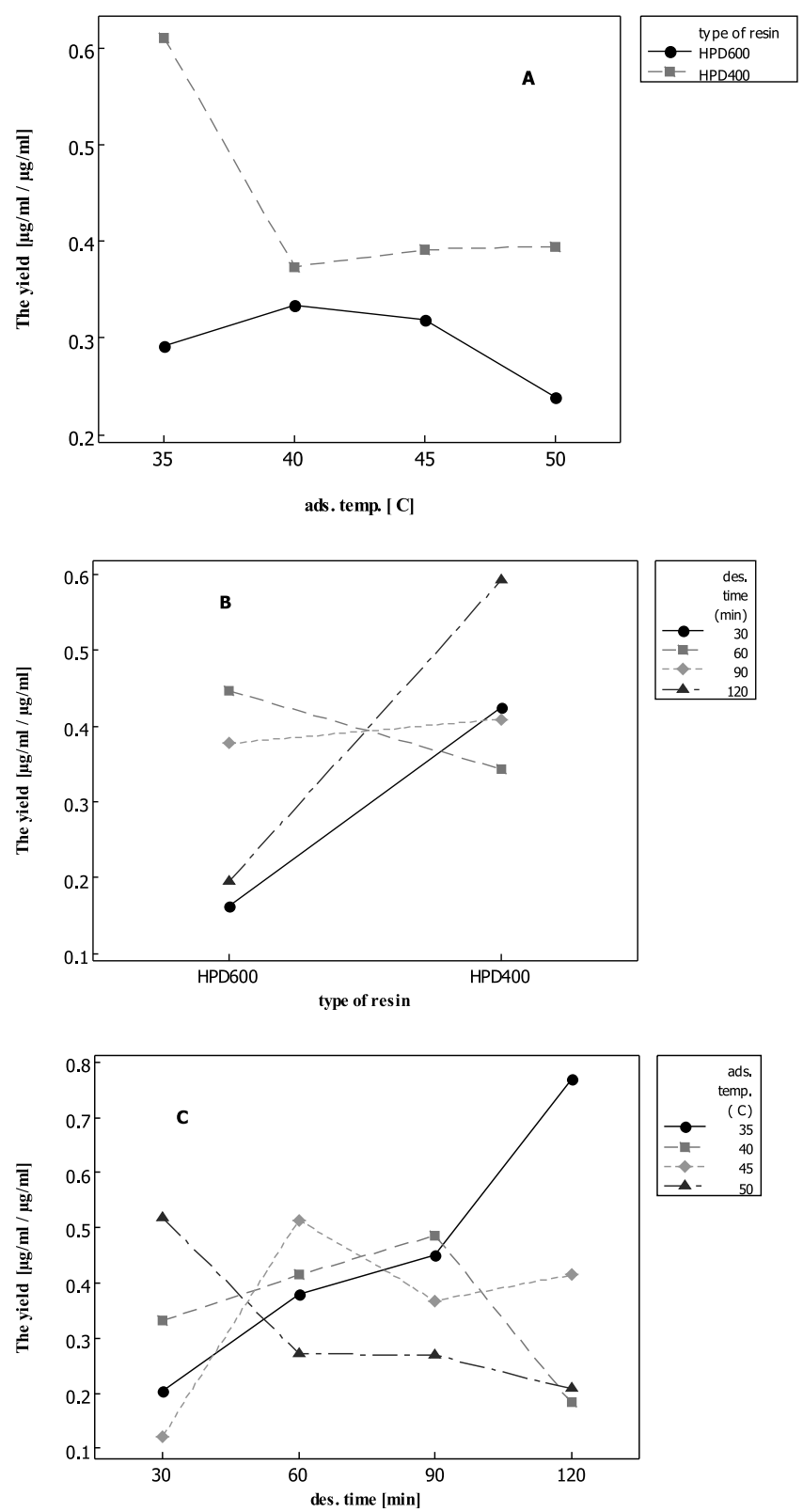

Figure 2. The interaction effects of the variables for the rebaudioside A yield based on the Taguchi experimental design results

showed that in $50^{\circ} \mathrm{C}$ the extraction yield decrease with desorption time increasing but adversely it increased in $30^{\circ} \mathrm{C}$ (Fig. 2C).

\section{Analysis of the experimental design}

The rebaudioside A yield was found to range from 0.121 to 0.771 in response to the variation in the experimental conditions (Table 2). The results from the analysis of the experimental design are shown in Table 3. The degree of significance of each factor is represented in Table 3 by its $p$-value, when a factor has a $p$-value of less than 0.05 it influences the process in a significant way for a confidence level of 0.95 . The results obtained show that

Table 3. Analysis of variance of the regression parameters for the Taguchi experimental design

\begin{tabular}{|l|c|c|c|c|c|}
\hline Source & D. F. & Sum of square & Mean square & $F$-value & $p$-value \\
\hline Adsorp. temp. $\left[{ }^{\circ} \mathrm{C}\right]$ & 3 & 0.078 & 0.026 & 60.78 & 0.016 \\
\hline Desorp. time [min] & 3 & 0.058 & 0.019 & 45.79 & 0.021 \\
\hline Elution ratio & 3 & 0.466 & 0.155 & 363.16 & 0.003 \\
\hline Adsorp. volume [ml] & 3 & 0.010 & 0.003 & 8.25 & 0.110 \\
\hline Type of resin & 1 & 0.170 & 0.170 & 397.45 & 0.003 \\
\hline Residual error & 2 & 0.0008 & 0.0004 & - & - \\
\hline Total & 15 & 0.7828 & - & - & - \\
\hline
\end{tabular}


all of factors; adsorption temperature, desorption time, elution solution ratio and type of resin except adsorption volume were significant $(p$-value $<0.05)$. The results indicated that the elution ratios and type of resin were the major contributing factors to rebaudioside A yield.

The quality of the experimental of design developed was evaluated based on the value of coefficient of determination $\left(R^{2}\right)$. Coefficient of determination $\left(R^{2}\right)$ is defined as the ratio of the explained variation to the total variation and used to measure the degree of fitness. In this case, the $R^{2}$ value was 0.998 , that Joglekar and May ${ }^{20}$ suggested for a good fit of a model, $R^{2}$ should be at least 0.80. This implied that $99.8 \%$ of the variations for the rebaudioside $\mathrm{A}$ yield are explained by the independent variables and only $0.2 \%$ of the total variability in the response was not explained by the model. The relatively high value of $R^{2}(0.998)$ demonstrated a high degree of agreement between the experimental observations and predicted values (Fig. 3) ${ }^{\mathbf{1 0}}$.

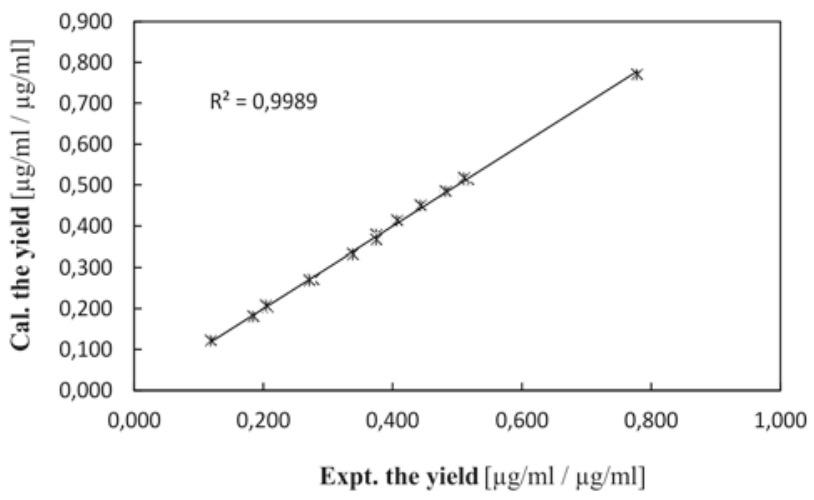

Figure 3. The relationship between the calculated the rebaudioside A yield and experimental data

\section{Optimum Conditions and Model Verification}

Optimum conditions for rebaudioside A purification was obtained using the Taguchi method as presented in Table 4. Under such conditions, the yield of extraction process was predicted to be 0.810 .

The suitability of the Taguchi orthogonal array for predicting the optimum response value was tested by additional independent experiments using the recommended optimum conditions. The results indicate that the extraction yield of rebaudioside A (0.789) is not significantly different from the predicted value $(0.810)$ (Table 4).

\section{ACKNOWLEDGMENT}

Financial support by Rasht Branch, Islamic Azad University Grant No. 4.5830 is gratefully acknowledged.

\section{CONCLUSIONS}

The preparative separation process of rebaudioside A with macroporous resins was developed in this work. The present investigation revealed that the application of DOE using Taguchi approach facilitated the process optimization by understanding the role of factors involved in the rebaudioside A yield. Furthermore, I also demonstrated that HPD-400 as resin was sufficient to increase of rebaudioside A yield under the conditions tested.

Table 4. Optimum conditions of the rebaudioside A yield, experimental and predicted from the Taguchi experimental design

\begin{tabular}{|c|c|c|c|c|c|c|}
\hline \multicolumn{3}{|c|}{ Optimum Condition } & \multicolumn{2}{c|}{ The extraction yield $\left[\frac{\mu \mathrm{g} / \mathrm{ml}}{\mu \mathrm{g} / \mathrm{ml}}\right]$} \\
\hline Adso. Temp. $\left[{ }^{\circ} \mathrm{C}\right]$ & Deso. Time [min] & Elu. Ratio & Adso. Vol. [ml] & Type of resin & Cal. value & Expt. value \\
\hline 35 & 65 & 3 & 200 & HPD-400 & 0.789 & 0.810 \\
\hline
\end{tabular}




\section{LITERATURE CITED}

1. Liu, J., Li, J. \& Tang, J. (2010). Ultrasonically assisted extraction of total carbohydrates from Stevia rebaudiana Bertoni and identification of extracts. Food Bioprod. Process. 88, 215-221. DOI: 10.1016/j.fbp.2009.12.005.

2. Wheeler, A., Boileau, A.C., Winkler, P.C., Compton, J.C., Prakash, I., Jiang, X. \& Mandarino, D.A. (2008). Pharmacokinetics of Rebaudioside A and stevioside after single oral doses in healthy men. Food Chem. Toxicol. 46, 54-60. DOI: 10.1016/j.fct.2008.04.041.

3. Geuns, J.M.C. (2003). Molecules of interest stevioside. Phytochemistry 64, 913-921. DOI: 10.1016/S0031-9422(03)00426-6.

4. Chatsudthipong, V. \& Muanprasat, C. (2009). Stevioside and related compounds: Therapeutic benefits beyond sweetness. Pharmacol. Therapeu. 21, 41-54. DOI: 10.1016/j. pharmthera.2008.09.007.

5. Liu, C., Li, L.S., Xu, L.L. \& Zhou, Z.M. (2007). Separation and identification of stevioside and Rebaudiodside A in Stevia by HPLC. Chinese J. An. Lab. 26, 23-26.

6. Zhang, Y., Chen, T.H., Shi, Z.Q. \& He, B.L. (1998). Studies on the separation of Rebaudioside A by recrystallization. Ion Ex. Adsorp. 14, 515-520.

7. Babic, K., Van der Ham, L. \& De Haan, A.B. (2006). Recovery of benzaldehyde from aqueous streams using extractant impregnated resins. React. Funct. Polym. 66, 1494-1505. DOI: 10.1016/j.reactfunctpolym.2006.04.013.

8. Liu, G.M., Zheng, S.R., Yin, D.Q., Xu, Z.Y., Fan, J. \& Jiang, F. (2006). Adsorption of aqueous alkylphenol ethoxylate surfactants by mesoporous carbon CMK-3. J. Colloid Interface Sci. 302, 47-53. DOI: 10.1016/j.jcis.2006.06.006.

9. Khayati, G. (2013). Optimization of Propionic Acid Extraction by Aqueous Two-Phase System Using Response Surface Methodology. Chem. Eng. Comm. 200, 667-677. DOI: 10.1080/00986445.2012.721032.

10. Khayati, G. \& Kiyani, F. (2012). A statistical approach for optimization of lipase production by using rice straw: analysis of different inducers and nitrogen sources effect. Minerva Biotecnol. 24, 83-89.

11. Anvari, M. \& Khayati, G. (2009). Optimization of 2,3-Butanediol Production by Klebsiella pneumoniae PTCC 1290 Using Taguchi Methodology. Asian J. Chem. 21, 2131-2140.

12. Behnajady, M.A. Hajiahmadi, M. \& Modirshahla, N. (2012). Enhancement of Removal Rate of an Organic Pollutant in the Presence of Immobilized $\mathrm{TiO}_{2}$ Nanoparticles with Inorganic Anions Combination: Optimization Using Taguchi Approach. Ind. Eng. Chem. Res. 51, 15324-15330. DOI: $10.1021 /$ ie301521z.

13. Erkucuk, A., Akgun, I.H. \& Yesil-Celiktas, O. (2009). Supercritical $\mathrm{CO}_{2}$ extraction of glycosides from Stevia rebaudiana leaves: Identification and optimization. J. Supercrit. Fluid 51, 29-35. DOI: 10.1016/j.supflu.2009.07.002.

14. Li, J., Chen, Z. \& Di, D. (2012). Preparative separation and purification of rebaudioside A from Stevia rebaudiana Bertoni crude extracts by mixed bed of macroporous adsorption resins. Food Chem. 132, 268-276. DOI: 10.1016/j. foodchem.2011.10.077.

15. Puri, M., Sharma, D., Barrow, C.J. \& Tiwary, A.K. (2012). Optimisation of novel method for the extraction of steviosides from Stevia rebaudiana leaves. Food Chem. 132, 1113-1120. DOI: 10.1016/j.foodchem.2011.11.063.

16. Fu, X.C., Shen, W.X. \& Yao, T.Y. (1990). Physical chemistry. Beijing: Higher Education Press, (Chapter 4), 172.

17. Chen, Z., Wei, X., Li, J. \& Di, D. (2012). Preparative separation of rebaudioside A from commercialized steviol glycosides by macroporous adsorption resins mixed bed. Sep. Purif. Technol. 89, 22-30. DOI: 10.1016/j.seppur.2012.01.001.

18. Xiong, Q., Zhang, Q., Zhang, D., Shi, Y., Jiang, C. \& Shi, X. (2014). Preliminary separation and purification of resveratrol from extract of peanut (Arachis hypogaea) sprouts by macroporous adsorption resins. Food Chem. 145, 1-7. DOI: 10.1016/j.foodchem.2013.07.140.

19. Wade, J.L.G. (1987). Organic Chemistry, Prentice-Hall, New York, 23-35.

20. Joglekar, A.M. \& May, A.T. (1987). Product excellence through design of experiments. Cereal Food World 32, 857-868. 